\title{
RANCANG BANGUN APLIKASI TELE-KENDALI KOMPUTER VIA JARINGAN PSTN DENGAN MODUL DTMF DAN MikRoKontroller ATtiny2313
}

\author{
Yuliadi Erdani, Hendy Rudiansyah \\ Jurusan Teknik Otomasi Manufaktur dan Mekatronika - Politeknik Manufaktur Negeri Bandung \\ Jl. Kanayakan No. 21 Bandung \\ Jawa Barat 40275, Indonesia \\ yul_erdani@yahoo.com; yul_erdani@polman-bandung.ac.id
}

Diterima: 27 Oktober 2010; Direvisi: 1 Desember 2010; Disetujui: 13 Desember 2010; Terbit online: 24 Desember 2010.

\begin{abstract}
Abstrak
Jarak pengendalian yang sangat jauh, target/aktuator yang sulit dijangkau, serta pembangunan jaringan pengendali yang sulit dan mahal, menjadi beberapa masalah dalam sistem pengendalian jarak jauh. Contohnya adalah dalam pengendalian komputer-komputer pada papan iklan digital/digital signage yang kerap disimpan di tempat-tempat yang sulit dijangkau, seperti di atas jembatan penyebrangan, di persimpangan jalan, dan sebagainya. Perusahaan pengelola kerap melakukan penonaktifan alat guna menghemat energi, namun belum ada alat yang memadai untuk mengendalikannya. Oleh karena itu, pengendalian dengan menggunakan jaringan telepon baik kabel maupun selular menjadi solusi yang tepat. Selain lingkup kendali yang sangat luas, telepon juga sangat mudah dioperasikan. Rangkaian aplikasi yang dikembangkan pada penelitian ini menggunakan dual tone multi frequency yang dibangkitkan melalui penekanan tombol telepon yang dijadikan data input pengendali mikrokontroller. Data frequency diubah menjadi data digital, lalu data tersebut dijadikan input pengendali mikrokontroller. Mikrokontroller kemudian mengendalikan komputer melalui relay dan port serial. Hasil percobaan menunjukan bahwa aplikasi yang dikembangkan ini mampu mematikan dan menghidupkan komputer serta perangkat lunak aplikasi pada komputer dari jarak jauh.
\end{abstract}

Kata kunci : dual tone multi frequency, tele-control, kendali dengan phone.

\begin{abstract}
Extremely long distance control, hardly reachable actuator/target and costly network development are some concerns whithin a distance control system. Such control is computer control for advertisements placed in tricky areas as locations over the bridge, at a junction, etc. The provider usually performs system inactivation in order to save energy. But until now, it is still difficult to find a system that can be turned on and off in remote manner. That is why the distant control using telephone can be the best alternative solution. Not only can the telephone be used in wide range of area, but also easily operated. The developed circuit in this research uses dual tone multiple frequency (DTMF). It is operated by pressing telephone button as control input for microcontroller. The microcontroller processes the input and controls the computer via relay and serial port. The result of experiment shows that the developed application is able to shut down and turn on computer as well as to apply software remotely.
\end{abstract}

Keywords: Dual Tone Multi Frequency, tele-control, control by phone.

\section{Pendahuluan}

Pengendalian jarak jauh di tempat-tempat yang sulit dijangkau membutuhkan jaringan komunikasi data pengendali yang memiliki jangkauan luas dan instalasi yang mudah sehingga pengaksesan objek yang dikendalikan dapat dilakukan dengan mudah dan efisien. Jaringan yang dimaksud adalah jaringan dengan ruang lingkup yang sangat luas, antar kota bahkan nasional atau internasional [1]. Salah satu yang memungkinkan adalah jaringan telepon, baik telepon seluler maupun telepon kabel [2].
Dalam penelitian ini, akan didalami tentang bagaimana memanfaatkan dual tone multi frequency (DTMF) pada telepon sebagai data input pengendali. Data frekuensi tersebut akan dikirim melalui hubungan telepon kemudian diterima dan diubah menjadi data digital. Data digital ini yang kemudian akan dijadikan input pengendali [3] [4]. Dengan adanya alat ini, pengendalian dalam lingkup yang sangat luas dapat dilakukan tanpa harus membangun jaringan komunikasi yang baru. 


\section{ISI MAKALAH}

Seperti terlihat pada diagram pada Gambar 1, alat pengendali ini dirancang untuk mengendalikan komputer dari jarak jauh melalui telepon. Pengendali dapat mengendalikan komputer dari mana pun selama alat dan pengendali masih berada dalam jangkauan jaringan telepon, baik sellular maupun kabel. Nada DTMF yang dapat terdengar ketika telepon tersambung dijadikan data input pengendalian. Sedangkan aktuatornya adalah relay dan program Computer Control pada komputer yang menerima perintah melalui komunikasi serial.

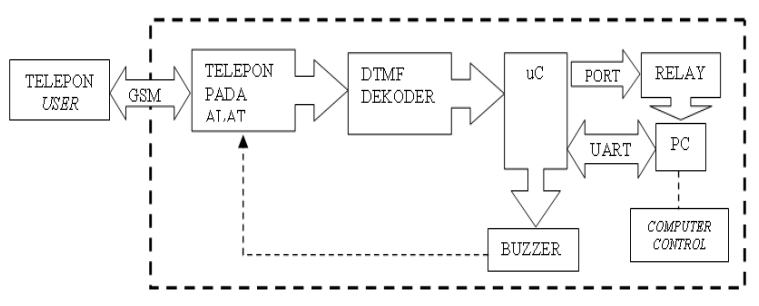

Gambar 1. Diagram blok sistem.

Relay dikendalikan langsung oleh mikrokontroller melalui salah satu port. Relay digunakan untuk menyalakan komputer, karena program Computer Control belum aktif. Sedangkan pengendalian melalui komunikasi serial digunakan untuk shutdown, restart, atau untuk mengaktifkan suatu program tertentu.

Telepon pada alat diatur agar menjawab secara otomatis. Ketika telepon tersambung, nada DTMF dikirimkan melalui sambungan telepon dengan menekan tombol pada telepon pengguna. Melalui port audio pada telepon penerima, frekuensi DTMF diterima dan diterjemahkan ke dalam data digital 4 bit oleh dekoder DTMF [5]. Mikrokontroller Attiny2313 sebagai pengendali menerima data tersebut sebagai input .

Sebagai penerima komunikasi dari mikrokontroller, program Computer Control harus disalin terlebih dahulu ke komputer yang akan dikendalikan. Program dibuat di Microsoft Visual Basic berupa berkas aplikasi [9] [10]. Program tersebut diatur agar aktif ketika start up. Sehingga ketika komputer aktif, pengendali sudah bisa mengendalikan komputer.

Tahapan pembuatan alat meliputi perancangan, pembuatan, dan ujicoba. Perancangan terdiri dari perancangan perangkat keras dan perangkat lunak. Untuk perangkat keras meliputi, rangkaian dekoder DTMF, sistem minimum mikrokontroller Attiny2313, dan transmisi komunikasi data antara mikrokontroller dan komputer melalui pengubah level tegangan TTLCMOS. Sedangkan untuk perangkat lunak meliputi program pengendali mikrokontroller menggunakan bahasa $\mathrm{C}$ dan program pengendali internal pada komputer yang dibuat menggunakan Visual Basic.

Tahap berikutnya adalah pembuatan alat, dimualai dari pembuatan perangkat keras, ujicoba perangkat keras, lalu dilanjutkan dengan pembuatan perangkat lunak. Terakhir barulah pengintegrasian antara perangkat keras dan lunak.

Masukan mikrokontroller berasal dari dekoder DTMF, yaitu 4 bit data hasil konversi dan 1 bit indikator pendeteksian nada DTMF. Kelima bit tersebut dihubungkan ke PINB.0 sampai PINB.4. Sedangkan 3 bit sisanya dialokasikan untuk keluaran. PORTB.5 untuk PWDN, PORTB.6 untuk buzzer, dan PORTB.7 untuk relay [8].

Pengkoneksian dua alat yang memiliki level tegangan berbeda harus melalui konverter level tegangan agar komunikasi dapat berlangsung. Seperti terlihat pada Gambar 3. 3 level konversi dari tegangan RS232 dan TTL maupun sebaliknya menggunakan IC MAX232. Level tegangan RS232 adalah -3 volt sampai dengan 25 volt merupakan logic high sedangkan 3 volt sampai dengan 25 volt merupakan logic low. Untuk level TTL, 5 volt merupakan logic high dan 0 volt merupakan logic low.

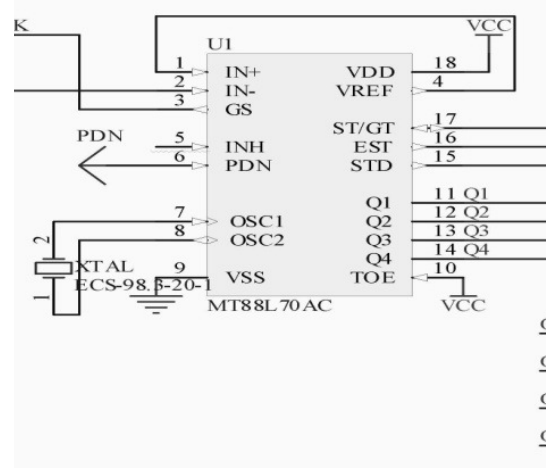

Gambar 2. Rangkaian dekoder DTMF.

Pada rangkaian sistem minimum Attiny 2313 telah terGambar bahwa pada intinya Receiver pada komputer menerima data dari transmitter mikrokontroller dan receiver mikrokontroller menerima data dari transmitter komputer. Sehingga komunikasi dua arah dapat dilakukan dengan menghubungkan port DB9 pada mikrokontroller (female) dengan DB9 pada computer (male) melalui kabel straight, bukan cross.

Rangkaian dekoder DTMF yang digunakan adalah rangkaian tipe Single Ended Input seperti terlihat pada rangkaian di Gambar 2. Keterangan lebih lengkap mengenai tipe rangkaian dapat dilihat pada datasheet MT88L70AC [10]. 
Pengaktifan buzzer menggunakan transistor dengan memanfaatkan salah satu fungsinya, yaitu sebagai sakelar elektronik. Pada alat ini, buzzer yang digunakan adalah buzzer 5V. Buzzer digunakan untuk memberi informasi kepada penelpon atas proses pengendalian yang berlangsung.

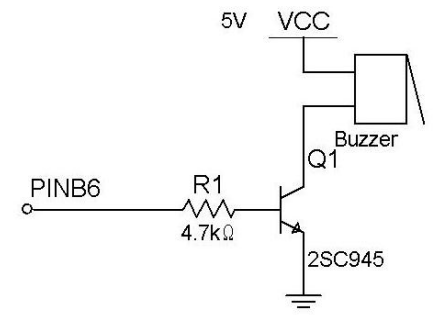

Gambar 3. Rangkaian buzzer.

Cara kerja rangkaian relay di bawah ini sama dengan rangkaian buzzer. Adapun fungsi relay pada alat ini adalah untuk mengaktifkan komputer. Kontak normally open (NO) dihubungkan ke pin Power On pada motherboard komputer, diparalelkan dengan tombol power komputer.

Ada dua jenis program yang diperlukan, program untuk mikrokontroller dan program Computer Control yang dibuat di Microsoft Visual Basic 6.0. Program Computer Control akan menjadi penerima perintah dari mikrokontroler. Data masukan ke mikrokontroller berupa kode penekanan tombol telepon dari dekoder DTMF [7]. Jika kode perintah benar, mikrokontroller akan mengirimkan data string ke komputer sebagai kode perintah (untuk shutdown, restart, atau mengaktifkan program) dan atau mengaktifkan komputer melalui relay sesuai dengan kode yang diterima. Jika tejadi kesalahan kode, mikrokontroller akan memberikan pemberitahuan error melalui buzzer yang akan terdengar oleh penelpon. Sebagai umpan balik kepada pengguna atas perintah yang berhasil dijalankan, mikrokontroller memberikan kode melalui suara buzzer yang diatur agar berbunyi dalam rentang dan konfigurasi tertentu.

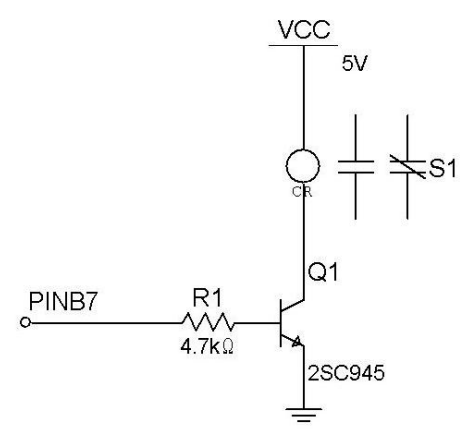

Gambar 4. Rangkaian relay.

Kedua program yang telah dituliskan di atas merupakan syarat yang harus dipenuhi guna terjadinya komunikasi antara computer dan mikrokontroller. Komunikasi yang digunakan adalah komunikasi UART (Unsynchronous) karena pendetakkan dari kedua alat yang berkomunikasi dilakukan masing-masing. Oleh karena itu, bagian utama yang harus diperhatikan adalah inisialisasi komunikasi serial tersebut, dari mulai pengaturan baud rate, data, paritas, dan port komunikasi yang digunakan. Berikut diagram alir program mikrokontroller dan Computer Control.

Program difungsikan untuk menerima dan mengolah input dari dekoder DTMF. Sebagai pengaman, setiap perintah terdiri dari 3 penekanan. Penekanan pertama sebagai kode lewat berupa penekanan tombol bintang, penekanan kedua sebagai pemilih perintah, dan penekanan ketiga berupa kode penutup berupa penekanan tombol pagar. Perintah hanya akan dijalankan jika ketiga kode tersebut benar. Jika kode salah, mikrokontroller akan memberikan umpan balik berupa kode error.
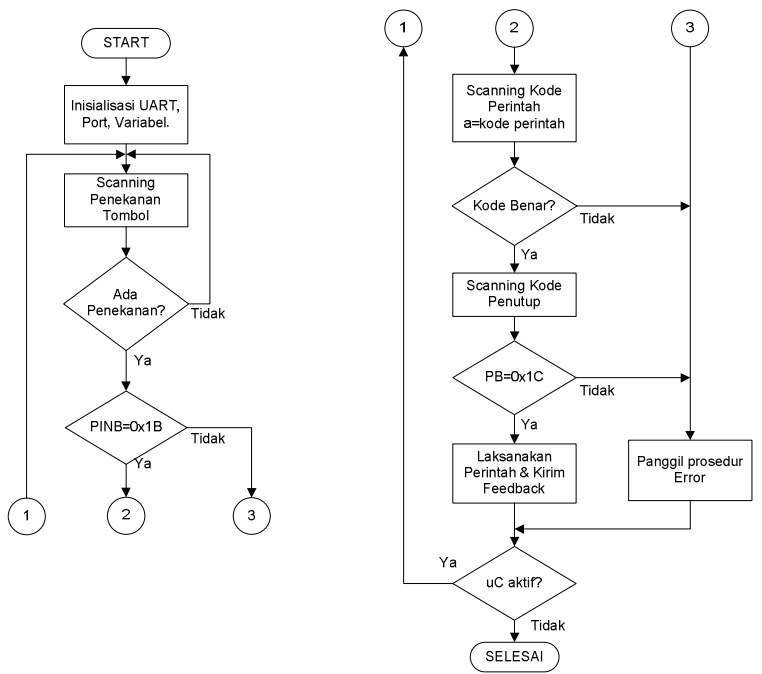

Gambar 5. Diagram alir program mikrokontroller. 
Untuk perintah mematikan, restart, dan membuka file, peran mikrokontroller adalah sebagai pengirim perintah ke komputer melalui komunikasi serial. Data yang dikirimkan berupa data string. Mikrokontroller akan memberikan informasi status perintah yang telah dikirimkan ke komputer setelah program Computer Control mengirimkan umpan balik kepada mikrokontroller. Informasi tersebut berupa bunyi buzzer dengan konfigurasi seperti terlihat pada Tabel 3.1.

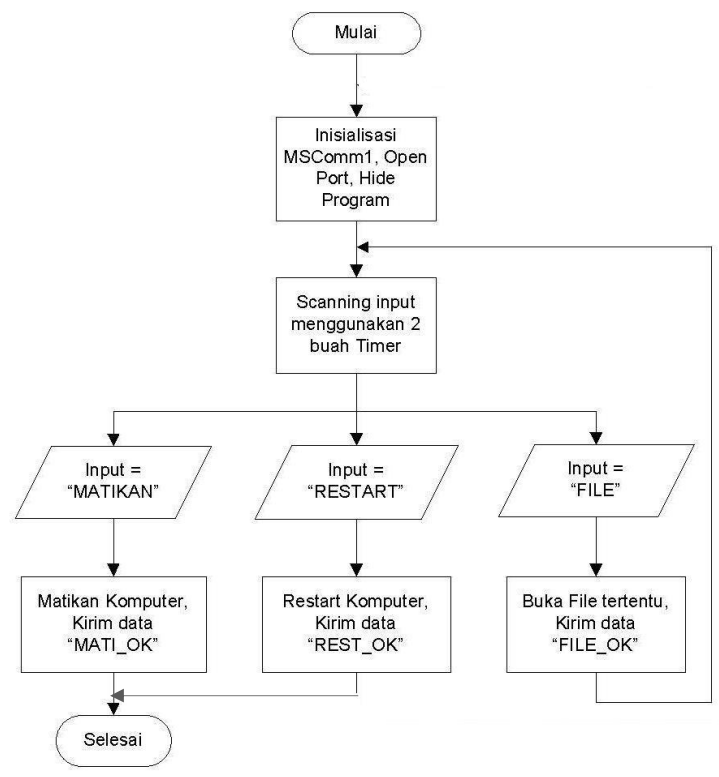

Gambar 6. Diagram alir program computer control.

Program menerima masukan berupa data string dari Mikrokontroller melalui komunikasi serial asinkron. Terdapat empat pilihan perintah yang dapat dikerjakan program tersebut, yaitu shutdown, restart, dan membuka file. Konfigurasi ini dapat diubah sesuai kebutuhan dengan merubah list program.

Tabel 1.

Data keluaran dekoder DTMF.

\begin{tabular}{cccc}
\hline Tombol & Keluaran & Tombol & Keluaran \\
\hline 1 & 0001 & 7 & 0111 \\
\hline 2 & 0010 & 8 & 1000 \\
\hline 3 & 0011 & 9 & 1001 \\
\hline 4 & 0100 & 0 & 1010 \\
\hline 5 & 0101 & $*$ & 1011 \\
\hline 6 & 0110 & $\#$ & 1100 \\
\hline
\end{tabular}

\section{Hasil \& Analisis Penelitian}

Pengujian bagian ini meliputi penggambaran gelombang nada DTMF sebagai masukan rangkaian DTMF dan pengecekan 4 bit data keluaran beserta 1 bit indikator pendeteksian nada DTMF.

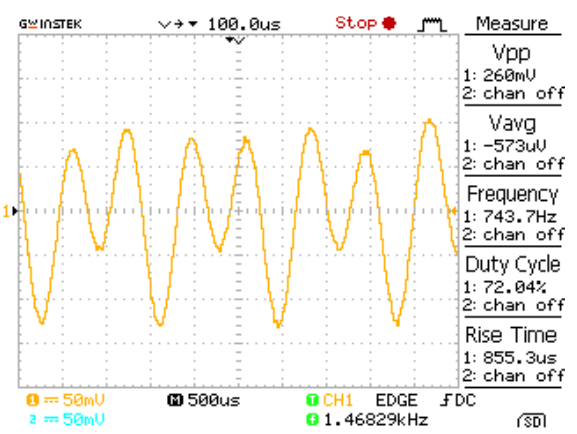

Gambar 7. Gelombang DTMF untuk Tombol 6.

Berikut daftar kode perintah beserta data yang dikirim ke komputer:

Tabel 2.

Input/output program mikrokontroller.

\begin{tabular}{ccc}
\hline Input & Fugsi & Data yang Dikirim \\
\hline$* 2 \#$ & Shutdown Komputer & "MATIKAN" \\
\hline$* 3 \#$ & Restart Komputer & "RESTART" \\
\hline$* 4 \#$ & Membuka FILE_A & "FILE_A" \\
\hline$* 5 \#$ & Membuka FILE_B & "FILE_B" \\
\hline
\end{tabular}

Dekoder mengeluarkan output data digital 4 bit dan 1 bit indikator pendetksian nada DTMF. Input mikrokontroller adalah data 5 bit dari dekoder DTMF yang merepresentasikan penekanan tombol-tombol telepon. Untuk keperluan pengamanan, input tersebut dibentuk ke dalam kode perintah tiga digit. 
Tabel 3.

Data String keluaran mikrokontroller.

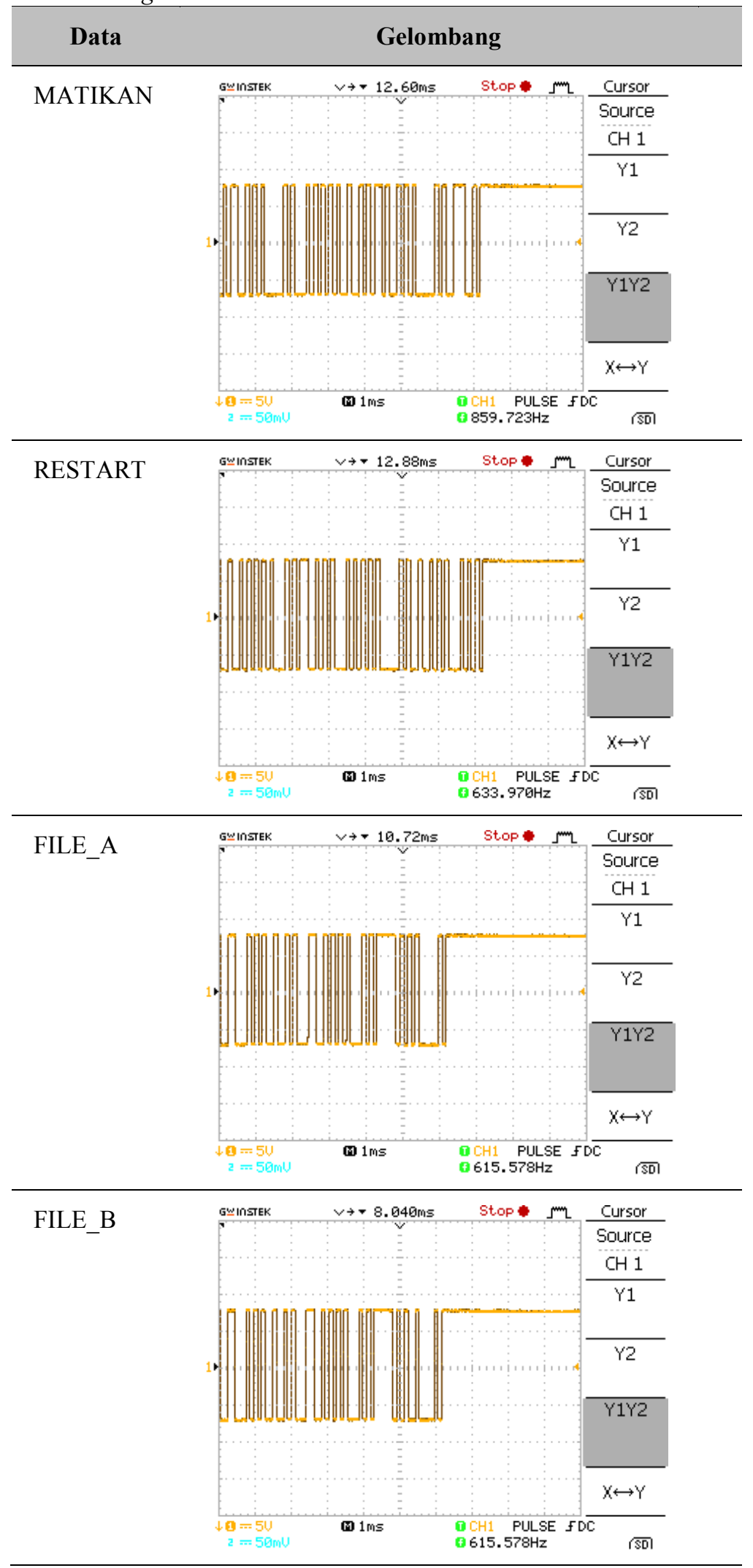

Program Computer Control ini befungsi sebagai pengendali internal komputer. Fungsi utamanya adalah untuk melakukan shutdown komputer, restart komputer, dan membuka file tertentu yang telah ditentukan sebelumnya. Fungsi tersebut dijalankan ketika program menerima perintah dari mikrokontroller. Untuk keperluan percobaan dan pengaturan manual, fungsi tersebut dibuat juga antarmukanya berupa tombol-tombol.

Program aktif bersamaan dengan aktifnya komputer dengan cara menyalin program pada 
folder Start Up. Gambar 8 Berikut menunjukkan tampilan antarmuka untuk program Computer Control dan tampilannya pada system tray.

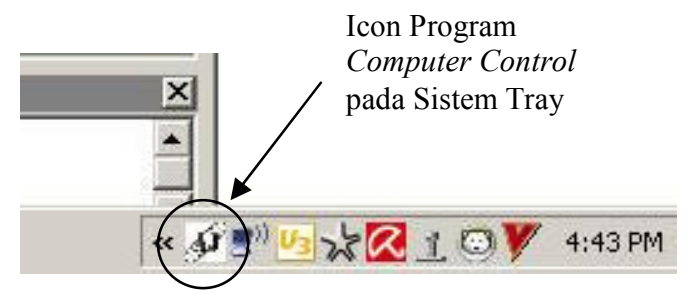

Gambar 8. Program computer control pada sistem tray.

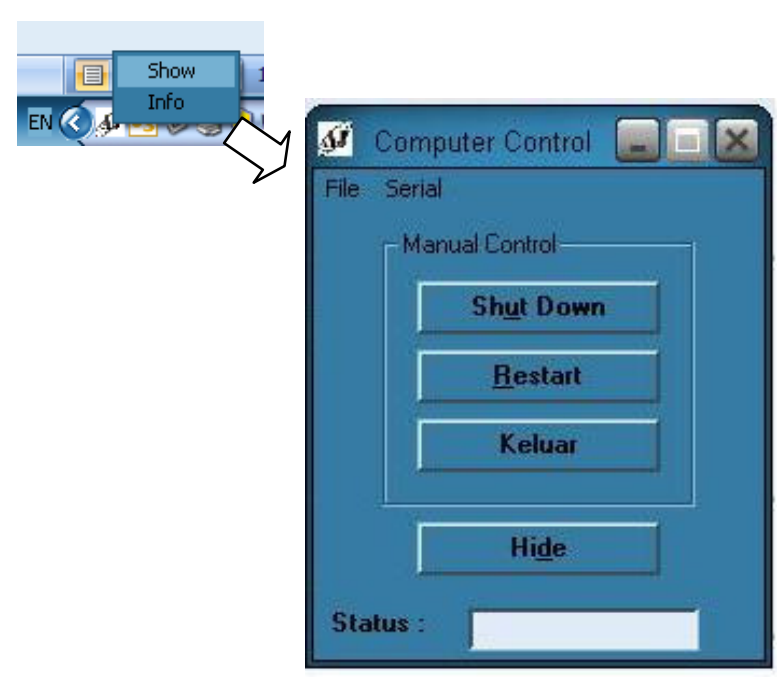

Gambar 9. Tampilan antarmuka program.

Program tersebut memiliki tiga perintah utama yang dapat dilaksanakan. Perintah utama tersebut masing-masing ditulis dalam satu prosedur. Prosedur dipanggil ketika data masukan sesuai dengan komparasi di program. Untuk pemindaian data masukannya itu sendiri digunkan 2 timer yang aktif bergantian dengan interval waktu $10 \mathrm{~ms}$.

\section{1) Scanning Data Masukan}

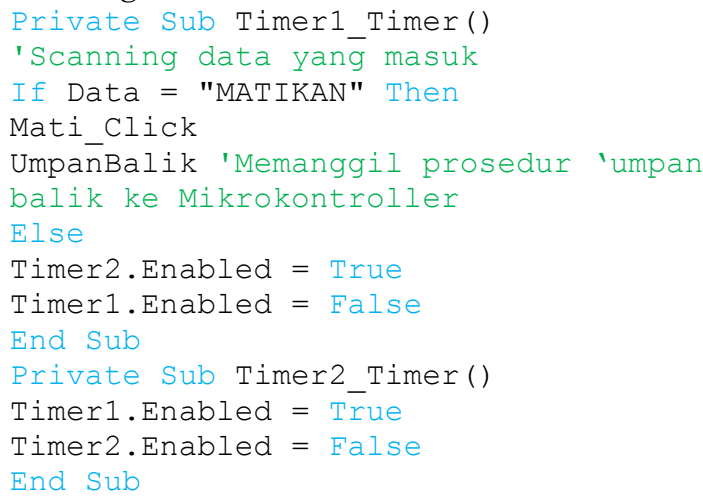

2) Perintah Shutdown Komputer Private Sub Mati Click() 'Prosedur untuk shutdown Shell "shutdown.exe -s -f -t o" End Sub

3) Perintah Restart

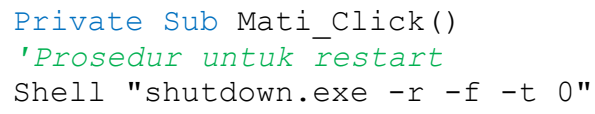

4) Perintah Membuka File

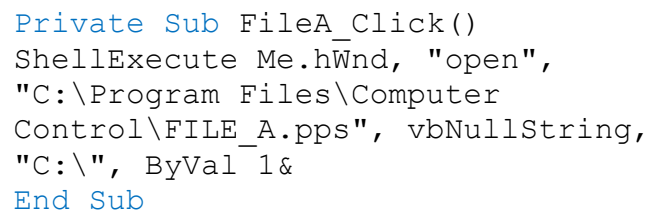

Program Computer Control melaksanakan pengendalian dan memberikan umpan balik kepada mikrokontroller dengan mengirim data string. Berikut daftar umpan balik untuk setiap perintah yang dilaksanakan.

Tabel 4.

Perintah dan data umpan balik computer control.

\begin{tabular}{cc}
\hline Perintah & Umpan Balik \\
\hline Shutdown Komputer & "MATIOK" \\
Restart Komputer & "RESTOK" \\
Membuka FILE_A & "FILEAOK" \\
Membuka FILE_B & "FILEBOK" \\
\hline
\end{tabular}

Fitur lain dari Program Computer Control adalah memungkinkannya pengaturan MSComm. MSComm dapat diatur pada menu MSComm Setting. Tampilan di bawah adalah pengaturan default program. Pengaturan diperlukan untuk mengganti salah satu properties dari MSComm jika diperlukan. Untuk menampilkannya, tekan menu serial lalu setting. Sedangkan dua sub menu lainnya adalah buka dan tutup port untuk menutup dan membuka port komunikasi yang digunakan.

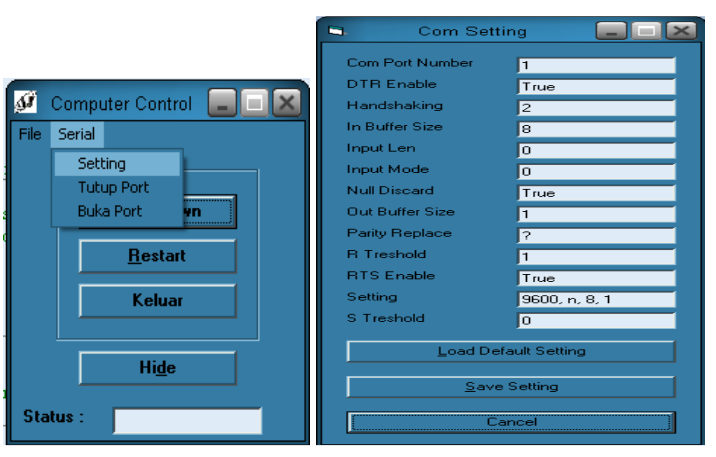

Gambar 10. Tampilan menu comm setting. 
Tabel 5.

Data string keluaran komputer ke mikrokontroller.

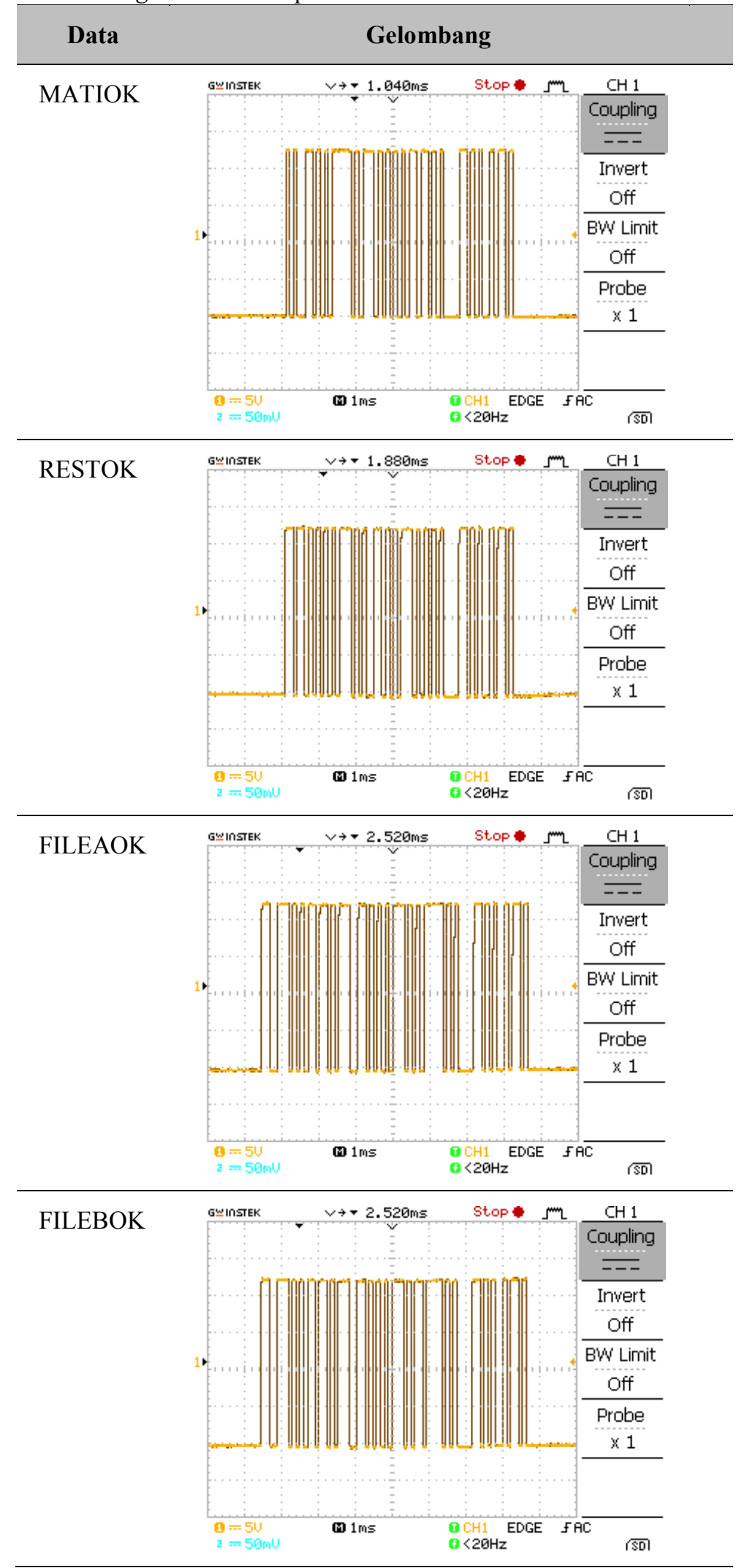

Semua data yang diambil merupakan data percobaan yang dilakukan berulang-ulang (sekitar 10 kali). Berdasarkan data yang diperoleh, sistem yang dikembangkan ini menunjukan suatu sistem yang cukup handal, karena menghasilkan data yang cukup stabil. Demikianpun dengan waktu tanggap sistemnya, sistem tersebut mampu memberikan respon dalam waktu yang cukup singkat, sesuai dengan desain, meskipun penggunaannya telah dilakukan secara berulangulang. 


\section{KESIMPUlan DaN SARAN}

Kesimpulan yang dapat diambil dari makalah ini adalah alat pengendali komputer ini menggunakan mikrokontroller Attiny2313 sebagai pengendali eksternal komputer dan program Computer Control sebagai pengendali internal komputer.

Pengendalian dilakukan dengan cara memanggil telepon pada alat lalu menekan kode perintah setelah panggilan dijawab secara otomatis.

Alat dapat digunakan untuk membuka file pada komputer, power on, shutdown, dan restart komputer.

Program Shutdown Control mengirim umpan balik ketika data perintah telah diterima mikrokontroller, lalu mikrokontroller mengirimkan informasi umpan balik dalam bentuk bunyi buzzer.

Ruang lingkup pengendalian mencapai lingkup global dan sangat bergantung pada ada tidaknya jaringan telepon.

\section{UCAPAN TERIMAKASIH}

Ucapan terimakasih disampaikan kepada $\mathrm{Sdr}$ Ajie Jamaludin, alumni AE Polman Bandung angkatan tahun 2007 yang telah membantu kelancaran kegiatan penelitian ini, serta kepada proyek I-MHERE melalui program Research Grant atas biaya yang diberikan untuk kegiatan penelitian ini

\section{Daftar Pustaka}

[1] Sharma, R.. et al., "DTMF based remote control system", IEEE International Conference, ICIT 2006. ISBN: 1-42440726-5

[2] Yun Chan Cho and Jae Wook Jeon, "Remote robot control system based on DTMF of mobile phone", Industrial Informatics, INDIN 2008. 6th IEEE International Conference, 2008. ISBN: 978-1-4244-2170-1
[3] Manojkumar, Mathankumar, Saranya, Pavithradevi, "Mobile controlled robot using DTMF technology", International Journal of Electronic Engineering Research., Volume 2 Number 3, pp. 349355, 2010. ISSN $0975-6450$

[4] T. Ramashri and P. Gangadhara Reddy, "Adaptive channel equalizer and DTMF detection", ARPN Journal of Engineering and Applied Sciences, Vol. 3, No. 2, April 2008. ISSN 1819-6608.

[5] Schenker, L., "Pushbutton calling with a two-group voice-frequency code", The Bell System Technical Journal vol:39, pp:235255, 1960. ISSN 0005-8580.

[6] I. Coskun and H. Ardam, "A Remote Controller for Home and Office Appliances by Telephone", IEEE Trans. Consumer Electron, vol. 44, no. 4, pp. 1291- 1297, November 1998

[7] Yavuz Erol, et al., "Safe and secure PIC based remote control application for intelligent home, IJCSNS International Journal of Computer Science and Network Security, VOL.7 No.5, May 2007

[8] Wilson, Verne. 1989. Dual Tone Multi Frequency (DTMF), diakses pada 30 April 2010 dari www.national.com

[9] Octovhiana, Krisna D. "Cepat Mahir Visual Basic 6.0," IlmuKomputer.com. 2003

[10] Perry, Gregg., "Visual basic dalam 12 pelajaran yang mudah", Yogyakarta : Andi, 1995.

[11] Noname, "Datasheet Integrated DTMF Receiver MT88L70AC" 